\title{
UMA LEITURA DA OBRA OS DISCOS DO CREPÚSCULO DE CADÃO VOLPATO A PARTIR DE WALTER BENJAMIN
}

Abraão Carvalho Nogueira

\begin{abstract}
RESUMO
O estudo procura realizar a leitura da obra Os discos do crepúsculo (2017), do escritor paulistano Cadão Volpato (1956-), a partir das formulações estéticas desenvolvidas pelo ensaísta alemão Walter Benjamin (1982-1940). Essa perspectiva de leitura transita entre uma peculiar relação entre cidade, música e literatura. Passando pela reflexão a respeito da cidade moderna e pela concepção de Benjamin a respeito da reprodução técnica da arte, pretendemos encontrar neste autor, referências significativas para interpretarmos a experiência estética do ouvinte na referida obra de Cadão Volpato, desde a leitura dos textos benjaminianos Paris, Capitale du XIX Siècle (1939), L'ouvre d'art à l'époque de sa reproduction mécanisée (1936), e Origem do Drama Trágico Alemão (2011).
\end{abstract}

Palavras chave: Cadão Volpato. Literatura. Música. Cidade. Walter Benjamin.

\section{A READING OF THE WORK THE DISCS OF TWILIGHT OF CADÃO VOLPATO FROM WALTER BENJAMIN}

\begin{abstract}
The study seeks to read the work The Twilight Discs (2017), by São Paulo writer Cadão Volpato (1956-), based on the aesthetic formulations developed by the german essayist Walter Benjamin (1982-1940). This perspective of reading moves between a peculiar relationship between the city, music and literature. Going through the reflection about the modern city and Benjamin's conception of the technical reproduction of art, we intend to find in this author, significant references to interpret the listener's aesthetic experience in the referred work of Cadão Volpato, since reading the Benjamin texts Paris, Capitale du XIX Siècle (1939), L'ouvre d'art à l'époque de sa reproduction mécanisée (1936), and Origin of the German Tragic Drama (2011).
\end{abstract}

Keywords: Cadão Volpato. Literature. Music. City. Walter Benjamin. 
Nesse percurso de leitura, nos propusemos a estabelecer uma proximidade entre a literatura do escritor paulistano Cadão Volpato ${ }^{1}$ em seu livro Os discos do crepúsculo (2017), no qual o autor reserva lugar privilegiado para a música no tecido de sua narrativa em sua ambientação histórica urbana, e como perspectiva de interpretação as formulações estéticas benjaminianas. Essa problemática surgiu de um ponto de partida inicial, que articula em uma dimensão estética, a perspectiva de uma interpretação que procura sobretudo sustentar uma relação substancial e histórica entre cidade, música e literatura.

Compreendemos ser o livro de Cadão Volpato de significativa representatividade estilística e singular a partir de uma perspectiva estética que coloca como centro de sua literatura a música, que se envereda em uma dinâmica de temporalidade da memória que é tomada como ponto de elucidação fundamental de seu propósito literário neste livro. Logo na apresentação, de Mauro Gaspar, sob o título Música do declínio, sons do poente, temos já uma indicação de como a relação entre música e memória está originariamente situada como um traço essencial de sua literatura:

Eu ainda tenho fotos daquela época. Poucas, verdade. Mas nem sempre precisamos de fotos para lembrar. Pode ser um desenho, ou um acorde. A frequência crespuscular é um tom. É a música que flui dentro da gente e carregamos pela vida, que nos preserva e preserva nossa identidade, fora do cotidiano, da turbulência, como se fosse o som do coração. E é. (GASPAR, 2017, 11)

É justamente diante do tema da memória, que uma aproximação do pensamento de Walter Benjamin pode ser elucidada. Nesse roteiro de estudo, será importante então atentarmos para os problemas e questões que podemos encontrar em uma leitura da obra de Cadão Volpato através da filosofia de Walter Benjamin. A saber: Como interpretar uma obra que coloca em um lugar privilegiado a música nos domínios da literatura, a partir da filosofia de Benjamin, na qual não encontramos um ensaio em específico que aborde mais detalhadamente o tema da música?

1 Cadão Volpato nasceu em São Paulo em 1956. Além de escritor, é músico (fundador da banda Fellini, um clássico dos anos 80 , com a qual lançou seis discos), jornalista e ilustrador. Escreveu quatro livros de contos (Ronda noturna, Dezembro de um verão maravilhoso, Questionário e Relógio sem sol, todos lançados pela editora lluminuras), o infantojuvenil Meu filho, meu besouro (Cosac Naify, 2011), ilustrado pelo próprio autor, e o romance Pessoas que passam pelos sonhos (Cosac Naify, 2013)". In: Volpato, Cadão. Um mistério nos Electric Lady Studios (Formas Breves). Edição do Kindle.

Doutorando PPGL (UFES/2020). Mestrando em Artes PPGA (UFES/2019-). Mestre em Filosofia PPGFIL (UFES/2017). Professor orientador Licenciatura Letras EAD (IFES/CEFOR/2020). Brasileiro, residente em Vitória-ES. Email: abraao.carvalho@yahoo.com 
Em um primeiro momento, nosso horizonte de leitura terá como perspectiva investigar as elaborações teóricas benjaminianas que estão nos domínios do campo de estudo de suas concepções estéticas. Feito este percurso nos restará um outro problema: Como interpretar a obra Os discos do crepúsculo de Cadão Volpato tendo como roteiro de interpretação os domínios da reflexão estética proposta por Walter Benjamin? Nestes domínios, estamos percorrendo um caminho de leitura e interpretação, que possibilita encontrar através da reflexão estética benjaminiana, conceitos chave para pensarmos em uma possível filosofia da música a partir de Walter Benjamin. Essa linha de investigação, a encontramos no artigo Walter Benjamin e la música (2013) da pesquisadora italiana Tamara Tagliacozzo, que irá sustentar que "la riflessione di Walter Benjamin sulla musica e il legame de questa con una visione messianico-redentiva dell' esperienza e della conoscenza, del linguaggio e della storia"2 (TAGLIACOZZO, 2013, 3).

As reflexões de Benjamin a respeito da arte como um todo irão nos servir de ponto de partida para pensarmos o lugar da música no livro Os discos do crepúsculo de Cadão Volpato. Nessa abordagem o caminho de reflexão indicado por Tagliacozzo nos orienta a respeito do aparecimento da música na literatura do escritor paulistano. Um acontecimento de "sperienza", "conoscenza", "linguaggio" e "storia", assim Tagliacozzo elucida a possibilidade de uma reflexão a respeito da música a partir de Walter Benjamin. E é nesses domínios que a música aparece no tecido literário por entre os contos de Cadão Volpato.

Essa articulação entre a perspectiva estética de Walter Benjamin, e a literatura do escritor paulistano e letrista do grupo Felline na década de 80 na cidade de São Paulo, pode nos oferecer relevante caminho de interpretação a respeito das relações entre cidade, música e literatura. É nesse campo da reflexão estética, no qual o filósofo e ensaísta Benjamin possui ampla, comentada e discutida produção, que encontramos uma referência de leitura em plena interlocução com alguns temas que aparecem no livro Os discos do crepúsculo.

A música estaria na condição de manifestar em seu acontecimento sua ultrapassagem dos domínios puramente estéticos, e participar de aspectos mais

\footnotetext{
2 "a reflexão de Walter Benjamin sobre a música e sua ligação com uma visão messiânico-redentiva da experiência e do conhecimento, da linguagem e da história" (tradução nossa). 
amplos da vida humana. Os discos do crepúsculo é uma obra que em sua teia narrativa, a referência à música é o traço essencial que aparece como o modo de enunciação e memoração constitutivo de sua literatura, mediado pelo rastro das imagens das capas dos discos que marcaram uma vida, ou no caso a vida de seus personagens, ora músicos, ora ouvintes, ora no âmbito da experiência estética, ora deslocados dela. Este cenário apresenta um preciso contexto histórico: a cidade de São Paulo dos anos 80 como ponto de partida, embora a dinâmica do livro Os discos do crepúsculo faça referência a outras cidades ao redor do mundo, tais como o Village em New York ou Montevidéu. A memoração através da música contudo, aparece desde os primeiros trechos do livro. É assim que encontramos no primeiro conto da obra de Volpato: Supersônica. A ambientação de referências estéticas e sonoras aparece em uma mera descrição da fisionomia de um dos músicos-personagens do conto:

Fred estava na loja quando viu se aproximar um garoto com um cabelo crespo armado como um black power, um cara muito branco, de olhos muito pálidos e uma expressão de contentamento ao estender-lhe a mão: era Afonso, mas todo mundo chamava de Fon. Fon era engraçado. Parecia Noel Redding, o baixista de Jimi Hendrix. Ele estava ali mesmo, entre outros discos, na capa psicodélica de Are you Experienced? que Fred segurava em seu ponto imóvel do tabuleiro, encostado na prateleira" (VOLPATO, 2017, 20).

A ambientação narrativa que lança discos pelas palavras na literatura de Cadão Volpato, traz à tona a reflexão a respeito de uma experiência estética originária, através da qual, o contar a cada nova experiência, pode ser atravessado por uma memoração de natureza sonora ou é constituinte de seu elucidar narrativo. A referência a Jimi Hendrix ao início do livro no conto Supersônica, torna-se trama narrativa no conto Um mistério nos Electric Lady Studios. Jimi Hendrix sai diretamente da capa de um disco em um conto para se transformar em personagem em outro. $\mathrm{Na}$ trama, Hendrix é apenas um citadino. É um flanêur, na acepção benjaminiana, à deriva de acasos e consumos na cidade, tão vulnerável quanto transitório entre os passantes. Cadão Volpato parece querer destacar com este conto, o modo de ser ordinário do artista, como um entre outros na urbe.

É em tal perspectiva que interpretamos alguns aspectos a respeito do lugar do personagem Jimi Hendrix no conto Um mistério nos Electric Lady Studios de Cadão Volpato. Enquanto citadino, o músico é apresentado sobretudo em sua condição 
histórica, como habitante desse espaço comum, marcado pelo traço de fantasmagorie formulado pelo filósofo Walter Benjamin em seu ensaio Paris, Capitale du XIX Siècle (1939). Esta será também a ambientação da elaboração teórica benjaminiana que aborda o conceito de flâneur. O espaço, a paisagem, o horizonte de relações sociais e culturais, está precisamente marcado por uma historicidade emblematizada no que Benjamin chama de "fantasmagoria" da cidade moderna. De acordo com o artigo Fantasmagoria: a chave para compreensão da modernidade em Walter Benjamin, de Francisco Santos: "a fantasmagoria seria para Benjamin uma imagem criada pelo homem, que adquire uma realidade própria, passando a ser ilusória e independente daquele que a criou" (SANTOS, 78, 2016). Portanto o conceito de fantasmogoria transita nos domínios da imagem que o sujeito cria ante a mercadoria. A fantasmagoria das mercadorias, que tanto pode entreter a sensorialidade, quanto surpreendê-la. Ainda de acordo com Francisco Santos:

a fantasmagoria remete ao lado mais exuberante, visível, a um certo espetáculo da mercadoria, e dessa maneira ocasiona um impacto subjetivo nos que iam as exposições, pois nelas criam-se uma imagem paralela fantasmagórica - , que aos poucos toma o lugar da realidade, assumindo por fim o papel principal de imagem real do mundo" (SANTOS, 2016, 78).

É nesta precisa ambientação teórica que Benjamin compreende o flâneur em um primeiro momento: "l'expérience du flâneur, qui s'abandonne aus fantasmagories du marché”3 (BENJAMIN, 1939, 375). Cadão Volpato se refere ao seu personagem Jimi Hendrix justamente como situado nessa paisagem urbana enquanto seu cenário de fundo. Ao sair depois de uma noite de trabalho do estúdio Electric Lady, Volpato descreve a paisagem encontrada por Hendrix na rua pela manhã, na qual encontra uma:

\begin{abstract}
...luz natural que começava a banhar as fachadas dos edifícios mortos, as ruas ainda meio escuras cortadas lentamente por automóveis sonâmbulos, era bom para Jimi. Tão bom que ele procurava um café para sentar e obter uma perspectiva ainda melhor do carrossel parado prestes a iniciar seu giro infernal. Afinal, trabalhara a noite inteira (VOLPATO, 2017, 91).
\end{abstract}

O músico no café da cidade na condição de deslocado de sua experiência estética sonora originária, com a finalidade de "sentar e obter uma perspectiva ainda

\footnotetext{
3 "a experiência do flâneur, que se abandona às fantasmagorias do mercado" (tradução nossa). 
melhor". Essa ambientação histórica e espacial descrita por Cadão Volpato no conto Um mistério nos Electric Lady Studios para seu personagem, nos remete à condição do flâneur benjaminiano, em seu abandonar-se ao olhar, à perspectiva, daquele que observa à dinâmica de uma cidade entregue às fantasmagorias possibilitadas pelo mundo dos objetos, dos bens produzidos, isto é, por suas mercadorias. Nesta ambientação urbana o Jimi Hendrix de Cadão Volpato é lançado à sua condição exclusiva de cidatino flâneur, deslocado de seu fazer artístico e situado no contexto da urbe moderna, seu lugar passagem. É desta forma que Volpato descreve Jimi em sua ida ao café da cidade, como o artista deslocado de sua experiência estética, isento da forma como sua música é apropriada e usufruída pelo público ou por si mesmo, e distanciado do resultado de sua arte em mercadoria, somente em sua condição espacial e temporal enquanto habitante da urbe:

\footnotetext{
A caminho do café, Jimi não era o tal. O cabelo nem estava muito armado, e o bigode, raspado nas semanas anteriores, voltava a crescer com as pontas na direção do queixo. Vestia uma camisa azul de tecido comum, e a calça era de um algodão qualquer, de cor escura. As botinas não brilhavam, e nenhum adereço exótico pendia do seu pescoço.

Ali estava o rei despojado de seu manto, de óculos escuros, um plebeu em cuja cabeça também não havia nenhum vestígio de coroa ou chapéu emplumado.

Ele encontrou um pequeno café aberto numa esquina a três quarteirões dos Electric Lady. Chamava-se Guatemala, um nome impossível de pronunciar" (VOLPATO, 2017, 92).
}

Precisamente neste momento do conto de Cadão Volpato, por um instante a figura estética do músico goza de sua condição de flâneur na urbe em seu horizonte contemplativo e desinteressado. Contudo, a trama de Volpato no conto Um mistério nos Electric Lady Studios não encerra-se nesse aspecto da acepção benjaminiana do flâneur, como veremos mais adiante. Tal constatação nos lança para uma problemática inerente à concepção de flâneur em Benjamin: Como compreender o flâneur no contexto da concepção benjaminiana de fantasmagorie? Essa dimensão contemplativa e desinteressada do flâneur, uma espécie de calmaria observante no contexto da urbe, mantém exclusivamente este traço em relação à concepção de fantasmogorie em Walter Benjamin? O que a concepção de fantasmagorie em Benjamin nos orienta a respeito dos traços e nuanças do flâneur?

No percurso do conjunto de tais reflexões, nos direcionamos a um outro 
problema interpretativo: Quais são precisamente os traços do flâneur emblematizado no personagem Hendrix do conto de Cadão Volpato? É no âmbito dessas problemáticas em torno do estatuto da concepção de flâneur, que uma aproximação mais estreita em relação às formulações benjaminianas em torno da cidade moderna irão nos orientar para o exercício de interpretação desse conto de Volpato, especificamente no que se refere aos desdobramentos da narrativa na qual o personagem Hendrix é lançado à sua condição histórica de cidatino do Village na década de 70.

Walter Benjamin em seus Écrits français (1991), que se constituem enquanto parte de seus trabalhos produzidos nos períodos em que esteve na França entre 1933 e 1940, precisamente ao seu ensaio Paris, Capitale du XIX Siècle (1939), que também faz parte de sua obra mais ampla e célebre Das Passagen-Werk ([1982] 2017), procura indicar os traços da vida urbana moderna tomando a cidade e a literatura francesa como suas principais referências teóricas de investigação. Benjamin destaca como traço essencial de sua leitura da metrópole parisiense o lugar da mercadoria nos domínios das relações na urbe, bem como, no que se refere ao modo como a paisagem urbana é apresentada em sua forma de exposição na condição de realçar - aspecto ludibriador da mercadoria que é a captura através do campo da sensorialidade. Tal aglutinação das relações sociais, culturais, destacada por Benjamin enquanto fortemente ambientada nos desdobramentos históricos e práticos da categoria de mercadoria se diluindo nas relações humanas, é também o aspecto do que Benjamin chama de um processo histórico no qual os fatos e a história, são reduzidos à condição de "forme de choses". De acordo com Benjamin:

\begin{abstract}
C'est là l'expression de la sensation de vertige caractéristique pour la conception que le siècle dernier se faisait de l'histoire. Elle correspond à un point de vue qui compose le cours du monde d'une série illimitée de faits figés sous forme de choses. Le résidu caractéristique de cette conception est ce qu'on a appelé »L'Histoire de la Civilisation«, qui fait l'inventaire des formes de vie et des créations de l'humanité... ${ }^{4}$ (BENJAMIN, 1939, 374.)
\end{abstract}

4 "Esta é a expressão da sensação de vertigem característica da concepção que o último século fez da história. Ela corresponde a um ponto de vista que compõe o curso do mundo através de uma série ilimitada de fatos fixados sob a forma de coisas. O resíduo característico desta concepção é aquela que se chamou de 'A História da Civilização', que faz um inventário das formas de vida e das criações da humanidade..." (tradução nossa). 
Esta será sua sustentação teórica para formular o conceito de "fantasmagorie", como o resultado dessa concepção que concebe a própria história como representação de coisas produzidas pela humanidade. A Capital do século XIX, teria sido uma expressão significativa da transformação da mercadoria em fantasmagoria. A concepção de fantasmagorie em Benjamin portanto é o aspecto crítico essencial da transformação do mundo dos objetos e da própria história a meramente coisas no contexto da modernidade. A sensorialidade será o alvo da produção de objetos de toda ordem, desde a arquitetura até literatura, passando pelo mundo das mercadorias. Tal ambição desenfreada de capturar a sensorialidade do passante na urbe, fugirá completamente de seu controle, e nesse contexto Benjamin a interpreta no sentido de uma fantasmagoria. Esta ambientação teórica é precisamente demarcada por Walter Benjamin no contexto de uma:

\begin{abstract}
...représentation chosiste de la civilisation, les formes de vie nouvelle et les nouvelles créations à base économique et technique que nous devons au siècle dernier entrent dans l'univers d'une fantasmagorie. Ces créations subissent cette ilumination non pas seulement de manière théorique, par une transposition idéologique, mais bien dans l'immédiateté de la présence sensible. Elles se manifestent en tant que fantasmogories. Ainsi se présentent les 'passages' première mise en oeuvre de la construction en fer; ainsi se présentent les expositions universalles, dont l'accouplement avec les industries de plaisance est significatif; dans le même ordre de phénomènes, l'expérience du flâneur, qui s'abandonne aus fantasmagories du marché ${ }^{5}$ (BENJAMIN, 1939, 375).
\end{abstract}

Benjamin procura demarcar sua leitura da cidade parisiense tendo como ponto de partida essencial sua historicidade, e sua crítica prossegue o itinerário da forma como a história é representada e como a própria cidade é compreendida nesta perspectiva. $O$ carácter de coisa dos objetos (deslocados de seus sentidos identitários ou estéticos), como o resultado de um contexto mais amplo sob o qual a cidade moderna é compreendida pelo filósofo e ensaísta alemão. O carácter de "forme de

\footnotetext{
"...representação da civilização através de coisas, as novas formas de vida e as novas criações a partir da base econômica e técnica que nós devemos ao último século entram no universo de uma fantasmagoria. Essas criações sofrem esta 'iluminação' não somente de maneira teórica, por uma transposição ideológica, mas através da imediaticidade da presença sensível. Elas se manifestam como fantasmagorias. Assim se apresentam as primeiras 'passagens', como obra da construção em ferro; assim se apresentam as exposições universais, cuja a união com as indústrias do entretenimento são significativas; na mesma ordem dos fenômenos, a experiência do flâneur, que se abandona às fantasmagorias do mercado" (tradução nossa).
}

Doutorando PPGL (UFES/2020). Mestrando em Artes PPGA (UFES/2019-). Mestre em Filosofia PPGFIL (UFES/2017). Professor orientador Licenciatura Letras EAD (IFES/CEFOR/2020). Brasileiro, residente em Vitória-ES. Email: abraao.carvalho@yahoo.com 
choses", de acordo com Benjamin, submete e condiciona o próprio olhar em relação à temporalidade histórica, uma vez que a "base économique et technique" está precisamente sob os desígnios de uma inclinação produtiva na qual o objeto produzido precisa estar na condição de oferecer o que Benjamin chama de "immédiateté de la presence sensible".

É neste terreno de "immédiateté de la presence sensible" que se move o flâneur, pois para Walter Benjamin, a cidade moderna parisiense na qual essa alegoria aparece como concepção teórica de significativa importância em sua leitura, do mesmo modo não escapa ao aspecto adverso da redução dos objetos à coisas de maneira irrestrita e vertiginosa, que se trata precisamente do que Benjamin irá nomear de fantasmagoria. Esse é espaço do flâneur benjaminiano, "que s'abandonne aus fantasmagories du marché" (BENJAMIN, 1939, 375).

Ora, o que então a concepção benjaminiana de fantasmagoria da cidade moderna pode nos orientar a respeito do aparecimento do flanêur de Cadão Volpato, o músico-personagem Jimi Hendrix deslocado de sua experiência estética nos domínios da trama narrativa do conto Um mistério nos Electric Lady Studios? Em outra parte do referido conto do livro Os discos do crepúsculo, Volpato nos oferece uma cena que pode ser emblemática no sentido de nos aproximarmos da concepção benjaminiana de fantasmagoria. Trata-se da cena em que o personagem Jimi é capturado de sua condição meramente observadora da urbe, e o seu instante no Café Guatemala depois da noite de trabalho no estúdio deixa de ser uma distração, para quase sucumbir colocando a própria vida em risco, em uma espécie de alusão à concepção de fantasmagoria no sentido benjaminiano.

Tal interpretação a respeito do aparecimento do traço de fantasmagoria no conto de Cadão Volpato com o seu personagem Jimi, pode ser levada adiante no sentido de que compreendemos fantasmagoria como um desdobramento adverso da relação com a objetivação da mercadoria, e precisamente na direção de traçar proximidades entre a concepção de Benjamin a respeito do flâneur, que está sobretudo ambientado nesta concepção de fantasmagoria das mercadorias, pois é neste âmbito e circunscrição espacial, a cidade, que ela transita.

Subitamente Hendrix observa um conhecido traficante do lugar em que estava no Café Guatemala no Village, e vai atrás do indivíduo. Essa mudança súbita em seu 
estar na urbe, no sentido benjaminiano enquanto o flâneur que "s'abandonne aus fantasmagories du marché", pode ser uma perspectiva interpretativa que se ajusta precisamente a esta cena do conto de Volpato, no sentido de que em última instância, o segundo personagem elucidado no conto pode ser interpretado como uma alegoria do consumo, e nessa dimensão, a interpretamos como o traço da fantasmagoria elucidada por Benjamin.

Tudo corria bem, na imobilidade desejada, e a manhã começava a ficar azul. Dentro de pouco tempo o movimento incessante recomeçaria, mas antes disso um homem magro e metido num casaco comprido, que nada tinha a ver com o verão, passou por ele e virou a esquina. Parecia dobrado sobre si mesmo.

Jimi conhecia o homem: era um pequeno traficante das redondezas. Ficou na dúvida entre abandonar a tranquilidade do café e correr atrás dele.

Decidiu pagar e sair às pressas, dobrando a mesma esquina. (VOLPATO, 2017, 93-94).

No conto de Volpato essa condição de ser capturado através do olhar por algo que nos remete à natureza do consumo de mercadorias, é levada ao extremo, uma vez que de uma página a outra no conto de Cadão Volpato o personagem Jimi Hendrix sai de sua calmaria no Café Guatemala do Village, para entrar em uma confusão a punhos e com direito a fuga pelas ruas da cidade, arriscando a própria vida e escapando por pouco. É nesta situação adversa que identificamos uma aproximação da concepção de fantasmagoria no sentido benjaminiano, uma vez que o desejo de consumo do Jimi de Volpato, irá voltar-se contra ele mesmo a partir do risco de violência e de barbárie. É uma forma possível de interpretar tal cena do conto de Volpato a partir da leitura de Benjamin e sua formulação teórica a respeito da cidade moderna a partir da concepção de fantasmagoria:

Foi um desastre. Os dois homens trocaram um rápido olhar e baixaram até o chão. Jimi se levantou assim que o outro puxou um canivete longo, que se abriu automaticamente.

Jimi deu um empurrão no cara e conseguiu fugir. Saiu correndo sem direção pelas ruas, louco e livre como num sonho em que as responsabilidades ainda não tivessem começado. Ria enquanto arfava, e assim desapareceu. Seus passos ecoaram numa rua desconhecida, as pernas diminuíram o ritmo e fizeram o movimento de um compasso em frente a um prédio do qual saía um rapaz sério. Jimi sorriu e coordenou uma larga passada por trás do indivíduo, com o intuito de impedir que a porta se trancasse" (VOLPATO, 2017, 94-95). 
Esta ambientação urbana no sentido da fantasmagoria elucidada por Benjamin, é o terreno sob o qual a música está sob um contexto delineado por sua historicidade. O músico-flâneur Jimi, deslocado de sua experiência estética, ambientado no espaço urbano, inebriado com o olhar a urbe no Café Guatemala e subitamente sob o risco de sucumbir por entre as ruas da cidade. Cadão Volpato parece querer destacar a relação ambígua entre música e cidade, no sentido de confrontar o tempo da experiência estética sonora com o tempo da experiência urbana sempre suscetível às fantasmagorias tal como o encontramos nas formulações benjaminianas.

Em outro texto disponível no site de Cadão Volpato, sob o título você nem imagina, referente ao nome de um álbum de 2010 de sua banda Felline, Volpato conduz sua narrativa a respeito do surgimento do grupo através da memoração de seu encontro com seu parceiro musical Thomas Pappon. O encontro foi na cidade de São Paulo, que parece fazer parte da ambientação da memoração de Volpato de maneira alegórica. Dessa maneira Volpato narra o nascimento do Felline:

\begin{abstract}
Havia um bar comandado por um árabe musculoso, com um topete de Elvis. Dentro desse bar, numa das mesas de fórmica, numa noite do meio da semana, Thomas Pappon trouxe a ideia de uma banda em que ele, baterista dos Voluntários e do Smack, tocasse baixo. E na qual eu (hmm) cantasse e fizesse todas as letras. Estávamos nos primeiros meses de 1984, a invasão brasiliense estava prestes a acontecer, nascia o Fellini.

Por que diabos a gente batizou a banda de Fellini? Porque foi o primeiro nome que apareceu. E, de certa forma, o tempo acabou ajustando o nome ao projeto: éramos de São Paulo, onde está a maior colônia italiana do mundo; Fellini estava vivo (e, para mim, Amarcord tinha sido uma revelação, um marco sexual da adolescência, por causa da célebre cena da tabaqueira; e eu ainda não achava A Doce Vida o seu melhor filme); observe o perfil romano do vocalista; e assim por diante.

Chamamos o Jair Marcos, um guitarrista da Mooca de delicadas tessituras sonoras. E pensamos no Ricardo Salvagni para tocar bateria, já que ele tinha aulas com o Victor Leite, um veterano da cena. Foi na lavanderia da casa do Ricardo, no Morumbi, que nasceram nossas primeiras músicas. Era sempre sábado, e sempre sábados ensolarados" (VOLPATO, 2010. In: cadaovolpato.com.br).
\end{abstract}

Música e cidade em uma dinâmica de historicidade de maneira a se encontrarem em um mesmo contexto originário de uma teorização e projeção criativa, visando uma experiência estética. Tal experiência estética elucidada no terreno da cidade de São Paulo da década de 80 como o descreve Cadão Volpato a respeito do surgimento do Felline, aglutina no conjunto de suas formulações, um modo específico e particular voltado para delimitar através da linguagem significações de um modo único de

Doutorando PPGL (UFES/2020). Mestrando em Artes PPGA (UFES/2019-). Mestre em Filosofia PPGFIL (UFES/2017). Professor orientador Licenciatura Letras EAD (IFES/CEFOR/2020). Brasileiro, residente em Vitória-ES. Email: abraao.carvalho@yahoo.com 
conceber a experiência estética e a concepção musical em seu vir a ser. A arte do cineasta Felline como referência demarca um modo de aproximação de referências estéticas que demarcam o campo de atuação e criação das composições musicais. $E$ a cidade como a possibilidade de promover esse encontro criativo do qual surgem diversos modos de expressão musical. A narrativa de Volpato no texto Você nem imagina em sua memoração de uma experiência urbana que antecede e origina o surgimento do grupo Felline, é elucidativo para demonstrar que na relação entre música e cidade, a música pode aparecer mesmo que ainda esteja silenciada ou em potencialidade latente.

Esta maneira peculiar de compreender o lugar da linguagem na concepção originária da experiência estética musical, tomando como elucidativo a narrativa de Volpato em relação ao surgimento do grupo paulistano Felline em sua memoração narrativa e explicitação da referência ao cineasta Felline como uma espécie de aproximação cultural e identitária, aparece como forma de tomar a arte como referência de conhecimento lançada à sua condição de relevante e significativa orientação teórica. Tal leitura nos aproxima da interpretação de Tamara Tagliacozzo no artigo Walter Benjamin e la música (2013), nos indicando que a possibilidade de pensarmos o lugar da música no contexto da ambientação teórica crítica e estética de Benjamin, nos possibilita pensar tal lugar no conjunto da "teoria della conoscenza e di teoria del linguaggio di Benjamin" (TAGLIACOZZO, 2013, 6).

O lugar da arte, e nesses domínios, a música, a partir das formulações de Benjamin, seguindo o itinerário da leitura de Tagliacozzo, nos aproximam das teorias do conhecimento e da linguagem formuladas por Benjamin. De acordo com a pesquisadora italiana, o ensaísta Walter Benjamin teria desenvolvido pontos de partida para a reflexão a respeito da experiência estética da música: "fondando la sua teoria (critica) della conoscenza su una concezione teologica e sulle idee-nomi come dimensione della totalità e luogo della veritá che si espone simbolicamente. $6 . . "$ (TAGLIACOZZO, 2017, 7). Tal perspectiva se sustenta nos domínios de uma concepção que parte da formulação e compreensão "trascendentale dall'arte" (TAGLIACOZZO, 2017, 10).

\footnotetext{
6 "fundando sua teoria (crítica) do conhecimento em uma concepção teológica e em ideias-nome como dimensão da totalidade e do lugar da verdade que é exposta simbolicamente..." (tradução nossa). 
Ainda de acordo com Tagliacozzo, essa concepção transcendental da arte que se aplica por extensão à experiência estética da música a partir do ensaísta Walter Benjamin, é o caminho de orientação de uma perspectiva teórica a respeito da música desde o seu aspecto de redenção e transcendência. É nessa direção que Cadão Volpato esboça de certo modo logo ao início de seu texto Você nem imagina, de forma elucidativa tal como um fragmento de história: "Como em todo tempo de repressão, a felicidade era clandestina" (VOLPATO, Você nem imagina, 2010).

Referindo-se ao contexto do nascimento do Felline, a banda de poemas tortos, como o elucida Volpato na canção Ventre Livre, uma das músicas do Felline do álbum Amanhã é tarde (2002). A partir de tal alusão redentiva e transcendental da música, ou a partir da experiência estética por ela suscitada no sujeito, é que uma aproximação entre Walter Benjamin e Cadão Volpato pode ser pensada, tomando a distância do delineamento das particularidades de cada um em suas respectivas elaborações, de modo a tomar tal relação como elucidativa no contexto das relações entre música, literatura e cidade.

Diante de um mesmo contexto de fantasmagorias da cidade moderna, a partir das acepções benjaminianas, Cadão Volpato pode representar uma leitura significativa para a elucidação da concepção transcendental da arte, como possibilidade de redenção, uma forma de felicidade clandestina, concepção na qual a aproximação com a arte se dá de maneira deslocada dos desígnios das "fantasmagories du marché" comentadas por Walter Benjamin enquanto a sustentação de sua crítica. É neste âmbito de reflexão, que Tagliacozzo procura sustentar que as formulações de Benjamin sugerem uma "visione messianicoredentiva della storia e della musica" (TAGLIACOZZO, 2017, 11).

Tal inclinação da perspectiva benjaminiana demarcada por Tagliacozzo a respeito da música, sugere uma aproximação com a experiência estética musical como deslocada de sua experiência enquanto objeto do mundo das fantasmagorias das mercadorias, pois assegura sua dimensão transcendental, e lança para o campo da criação, uma condição que possibilita um modo peculiar de expressividade, através de uma forma de linguagem redentora da fantasmagoria da cidade moderna na acepção benjaminiana. Cadão Volpato através de sua obra Os discos do crepúsculo, particularmente em referência a um outro conto evocado a partir de um disco do grupo 
inglês Durutti Column, parece querer reservar sua narrativa para um outro modo de experiência estética musical no qual tal deslocamento de sua condição de redução ao seu aspecto como objeto-coisa por entre as fantasmagorias das mercadorias, é por sua vez, essencial para a natureza mesma dessa possibilidade de experiência estética.

As canções do álbum Amigos de Portugal (1983) do Durutti Column, objeto da memoração narrativa no conto Levamos um mundo novo em nossos corações, elucidam de certa maneira, essa possibilidade da experiência estética através da música, neste caso em específico a experiência estética do ouvinte do disco de vinyl que faz parte do imaginário narrativo de Cadão Volpato nos elucidando essa experiência. Sobremaneira, Volpato nos possibilita vislumbar em sua narrativa que o primordial ao tratar da música do Durutti Column é conceber tal experiência sonora como uma referência de visão estética na qual este modo de arte preserve sobretudo sua condição de transcendência no sentido metafísico atribuído a este conceito no campo da discussão estética, e nos domínios de sua própria natureza, concebe-se enquanto deslocada do mundo das fantasmagorias da cidade moderna, aspecto essencial da crítica benjaminiana.

A concepção de Tagliacozzo sustenta a leitura de que as condições para pensarmos em uma possível filosofia da música a partir de Walter Benjamin, nos aproximam da perspectiva teórica de sua "teoria (critica) della conoscenza", a partir de uma "concezione teologica del linguaggio", sob uma "dimensione della totalitá e luogo della verità", que por sua relevância no âmbito de seus pressupostos teóricos, nos indicam precisamente a respeito da importância da música no contexto das formulações estéticas de Benjamin. A música como uma experiência de conhecimento transcendental, no âmbito de sua concepção de linguagem.

Música e conhecimento, num enlace de aparecimento de verdade, que mesmo em sua particularidade, apresenta algo da natureza de uma verdade no âmbito de uma totalidade, assim Walter Benjamin, seguindo a orientação de leitura proposta por Tagliacozzo, compreende o lugar da música. Esta compreensão de que através da experiência estética da música, encontramos uma forma de conhecimento enquanto modo de linguagem peculiar, é, portanto, compreendida nos domínios de uma teoria do conhecimento daí resultante. Nesta perspectiva, a música, assim como a arte no 
pensamento de Benjamin, se articula com o conceito de totalidade e verdade. Este caminho de leitura proposto por Tagliacozzo a partir do ensaísta Walter Benjamin, se aproxima do que o francês Jacques Atalli afirma na Introduction de sua obra Bruits: essai sur l'économie politique de la musique (1977). De acordo com Atalli:

La musique est plus qu'objet d'étude: elle est un moyen de percevoir le monde. Un outil de connaissance... Instrument de connaissance, elle incite à déchiffrer une forme sonore du savoir. Mon intention n'est donc pas ici seulement de théoriser sur la musique mais de théoriser par la musique ${ }^{7}$ (ATALLI, 1977, Introduction, 9).

A música como possibilidade de conhecimento, e no sentido a partir do qual Atalli compreende, é através da música que tal forma de conhecimento é possibilitada. Este através, e não sobre, significa a partir da música e em seus domínios, o encontro com um horizonte possível do "savoir". No conto de Cadão Volpato que se inicia com a referência a um disco do Durutti Column, o que encontraríamos diante da indagação: o que nos é levado a saber Volpato através deste conto? Outro tema essencial que atravessa o livro de Cadão Volpato, e que de certo modo procura sustentar o encadeamento de sua dinâmica narrativa, é a importância da discussão a respeito da fonografia. A recepção estética na condição de ouvinte do disco, a audiência, a distribuição, o contexto histórico cultural e musical do período, as referências políticas na concepção estética do artista escutado, estes serão os aspectos mais evidenciados por Cadão Volpato no conto levamos um mundo novo em nossos corações. Alguns destes aspectos são encontrados na seguinte passagem do conto:

Poucas pessoas no mundo ouviram Amigos em Portugal (foram lançadas apenas 4 mil cópias em vinil). Não muitas pessoas no mundo conhecem The Durutti Column, a banda de Manchester inventada em 1978 por Tony Wilson, o fundador do selo Factory, o mesmo do Joy Division e de outras bandas que nasceram depois do show histórico dos Sex Pistols na cidade, em 4 de junho de 1976, The Return of The Durutti Colunm foi o primeiro lançamento da Factory (VOLPATO, 2017, 109).

O artigo de Trahan, intitulado Phonographie, cinéma et musique rock. Autour d'un impensé théorique chez Walter Benjamin (2013), elucida um aspecto do pensamento

\footnotetext{
"A música é mais do que um objeto de estudo: ela é um meio de perceber o mundo. Uma ferramenta de conhecimento... Instrumento de conhecimento, ela incita a decifrar uma forma sonora de saber. Minha intenção não é somente teorizar sobre a música mais teorizar através da música (tradução nossa).
}

Doutorando PPGL (UFES/2020). Mestrando em Artes PPGA (UFES/2019-). Mestre em Filosofia PPGFIL (UFES/2017). Professor orientador Licenciatura Letras EAD (IFES/CEFOR/2020). Brasileiro, residente em Vitória-ES. Email: abraao.carvalho@yahoo.com 
de Walter Benjamin não tão discutido a partir de sua obra, que é a importância da phonographie na reflexão benjaminiana. Tal linha de estudo, deve-se certamente ao legado teórico de Walter Benjamin a partir de seu célebre ensaio L'ouvre d'art à l'époque de sa reproduction mécanisée (1936, Écrits français). O tema da reproduction mécanisée enquanto condição de produção das artes no contexto moderno, alterou significativamente a estrutura conceitual das concepções estéticas.

O conceito de reproduction mécanisée aparece no conto de Cadão Volpato a respeito do Durutti Column tanto no sentido da recepção estética do ouvinte da música do Durutti, quanto na identificação da concepção estética das composições das músicas do guitarrista inglês: "A música do primeiro disco do Durutti Column unia as guitarras sem distorção - afiadas, mas contemplativas e melancólicas - de Vini Reilly aos sintetizadores frios e baterias eletrônicas primitivas programados pelo produtor Martin Hannett" (VOLPATO, 2017, 111). Os domínios da discussão benjaminiana elucidados por Thahan se referem ao aspecto da recepção estética possibilitado através da produção fonográfica, e destacam a importância da interlocução com Walter Benjamin na abordagem de tais temas:

\begin{abstract}
suscite un impensé au couer de la théorie de Walter Benjamin sur la reproductibilité tecnique, à savoir l'importance de la phonographie. Le philosophe fut l'un des premiers à explorer la voie que consiste à tenter de compreendre comment des innovations technologiques modifient les théories esthétiques. Dans ses analyses célèbre, il chercha précisément à théoriser, à la suite d'une remarque de Paul Valéry, en quoi la partie physique d'une oeuvre et la technique transforment notre compréhension de ce qu'est l'art et permettent de construire de nouvelles subjectivités, de nouvelles visions du monde. Autrement dit, comment les inovations obligent les penseurs se penchant sur l'esthétique à s'interroger sur le fondement même de leur pratique et de leurs objets d'étude ${ }^{8}$ (TRAHAN, 2013, 104).
\end{abstract}

A alteração no modo da recepção estética desde a era da reprodução técnica da arte na acepção de Walter Benjamin, e elucidada a partir da narrativa de Cadão

\footnotetext{
8 "suscita o impensado no coração da teoria de Walter Benjamin sobre a reprodutibilidade técnica, a saber, a importância da fonografia. O filósofo foi um dos primeiros a explorar o caminho que consiste em tentar compreender como as inovações tecnológicas modificaram as teorias estéticas. Em suas célebres análises, ele procurou precisamente teorizar, seguindo uma observação de Paul Valéry, como a parte física de uma obra e a técnica transformam nossa compreensão do que é a arte e nos permitem construir novas subjetividades, novas visões de mundo. Dito de outro modo, como as inovações obrigam os pensadores a se apoiarem sobre a estética a fim de se interrogaram sobre o fundamento mesmo de suas práticas e de seus objetos de estudo" (tradução nossa).
} 
Volpato a respeito da música do Durutti Collumn, de acordo com o artigo de Trahan, Phonographie, cinéma et musique rock. Autour d'un impensé théorique chez Walter Benjamin (2013), é significativa a constatação que nos orienta que esse modo de recepção estética, marcada pelo traço da reprodução técnica no sentido benjaminiano, é capaz de "transforment notre compréhension de ce qu'est l'art et permettent de construire de nouvelles subjectivités, de nouvelles visions du monde". A reprodução técnica da arte, embora inicialmente assegure sua relevância no aspecto físico e material da obra de arte no contexto da modernidade, não pode portanto ser interpretada como somente de natureza objetiva, pois não se trata somente de uma identificação de um modo da experiência estética, seja na concepção ou na recepção, sendo também possibilitadora de transformações na subjetividade do sujeito. É o que Walter Benjamin parece querer destacar em seu ensaio L'ouvre d'art à l'époque de sa reproduction mécanisée (1936):

La technique de reproduction - telle pourrait être la formule générale détache la chose reproduite du domaine de la tradition. En multipliant sa reproduction, elle met à la place de son unique existence son existence en série et, en permettant à la reproduction de s'offir en n'importe quelle situation au spectateur ou à l'auditeur, elle actualise la chose reproduite"9 (BENJAMIN, 1936, 181).

Benjamin procura destacar esses dois aspectos da obra de arte no contexto de suas técnicas de reprodução: a saber, um traço que está sob os domínios da criação e produção artística e de sua distribuição, e outro, se refere ao modo como o objeto reproduzido é experienciado pelo sujeito estético. O primeiro aspecto preserva os domínios de uma constatação objetiva das condições materiais e históricas que atravesaram o modo de se conceber e de se produzir arte, de tal maneira que nos domínios da recepção estética, tanto o spectateur quanto o auditeur possuem o privilégio de "actualise la chose reproduite". Esta recepção estaria nos domínios da experiência estética através do objeto reproduzido, no sentido de possibilitar a "construire de nouvelles subjectivités" (TRAHAN, 2013, 104), de acordo com a leitura

\footnotetext{
9 "A técnica de reprodução - tal poderia ser a fórmula geral - separa a coisa reproduzida do domínio da tradição. Ao multiplicar a sua reprodução, coloca no lugar de sua única existência sua existência em série e, ao permitir que a reprodução seja oferecida não importe em que situação ao espectador ou ao ouvinte, ela atualiza a coisa reproduzida" (tradução nossa).

Doutorando PPGL (UFES/2020). Mestrando em Artes PPGA (UFES/2019-). Mestre em Filosofia PPGFIL (UFES/2017). Professor orientador Licenciatura Letras EAD (IFES/CEFOR/2020). Brasileiro, residente em Vitória-ES. Email: abraao.carvalho@yahoo.com
} 
de Trahan a partir dos textos de Benjamin.

Este traço de transformação da subjetividade indicado por Trahan, a respeito da recepção estética sob os desígnios da condição histórica moderna enquanto reprodutibilidade técnica, tal como a orientação de Benjamin de que o próprio sujeito ressignifica o objeto reproduzido quando de sua recepção enquanto auditeur, nos oferece valioso caminho de interpretação para a leitura de outra importante passagem do conto que versa a respeito da música do Durutti Column na narrativa sonora de Cadão Volpato:

\begin{abstract}
O segundo disco do Durutti Column se chamaria $L C$, uma citação do grupo ultraesquesdista italiano Lotta Continua. Como no caso anterior, a revolução de Vini Reilly eram as guitarras ('Uma pequena e misteriosa nuvem branca, constituída de cristais de gelo em suspensão no oxigênio úmido, atravessando devagar a terra desolada e barulhenta do punk na companhia de um velho baterista de jazz e de algumas quinquilharias eletrônicas', de acordo com a extravagante definição de um crítico da Mojo). Uma revolução de veludo" (VOLPATO, 2017, 111).
\end{abstract}

Os domínios da concepção estética a respeito da música do Durutti Column na narrativa sonora de Cadão Volpato, nos oferecem um exemplo de uma forma de recepção do objeto reproduzido, o disco, tal como o compreende Walter Benjamin, ao passo que o sujeito submetido ao experienciar como ouvinte a música do Durutti, a atualiza, e a resiginifica, como fica nítido a intenção de Volpato ao procurar oferecer importância para uma forma peculiar de expressão musical, que está deslocada de um reconhecimento de audiência mais amplo: "Não muitas pessoas no mundo conhecem The Durutti Collumn" (VOLPATO, 2017, 109). De fato, não há um só disco do Durutti por exemplo, listado na célebre obra 1001 Discos para ouvir antes de morrer (2011), com organização geral de Robert Dimery e com prefácio de Michael Lydon, este último editor fundador da Rolling Stone.

O que atesta para a pretensão de Cadão Volpato de tecer em sua narrativa com este conto, uma outra maneira de compreender a experiência estética do ouvinte. Tal experiência como ouvinte, nos aproximando agora da orientação de leitura de Tagliacozzo a respeito das relações entre o pensamento estético de Walter Benjamin e a música, estão situados como uma possibilidade de conhecimento e linguagem, de tal maneira que, de acordo com Tagliacozzo encontramos “...in Benjamin, una filosofia della musica che incrocia e investe la sua filosofia de la conoscenza e del linguaggio, la sua ética e la sua estética a partire de Sulla lingua in generale e sulla lingua 
dell'uomo fino all' Origine del dramma barroco tedesco..."10 (TAGLIACOZZO, 2013,13).

A indicação de Tagliacozzo de que a filosofia da música de Walter Benjamin pode ser elucidada a partir dos estudos de estética e linguagem desenvolvidos sobretudo na obra Origine del dramma barroco tedesco, será aqui de significativa importância para nos laçarmos a uma investigação dos pressupostos benjaminianos que poderão nos servir de referência teórica para interpretar o aparecimento da música na obra de Cadão Volpato. Ainda segundo Tagliacozzo, a música seria capaz de promover o imaginário de maneira involuntária, como se a música tivesse em sua natureza própria suscitar imagens de maneira involuntária no sujeito da experiência estética.

É nesta perspectiva que Tagliacozzo sustenta essa possibilidade de uma filosofia da música a partir de Walter Benjamin, e menciona outro autor, Carchia, em um trabalho intitulado Nome e immagine. Saggio su Walter Benjamin (2010): "Il tempo del ricordo è 'il tempo messianico - tempo della musica, dell' ideia linguistica o dell' immagine involuntarie"11 (TAGLIACOZZO, 2017, 14 apub CARCHIA, 2000, 120). Esta elucidação teórica, que interpreta a música como possibilitadora de imagens involuntárias, tal como nos indica Tagliacozzo em sua interlocução com Carchia, nos aproxima das formulações de Mirko M. Hall em seu ensaio Dialectical sonority: Walter Benjamin's Acoustics of Profane Illumination (2010). De acordo com Hall, a partir de suas leituras das obras The Complete Correspondence, Adorno and Benjamin (1999), e da obra The Origin of German Tragic Drama (1977), a potencialidade da música e do som estaria nesta condição de promover imagens. No itinerário de tal perspectiva, Hall interpreta que Benjamin teria atribuído natureza metafísica ao som e à música, no sentido de serem catalizadores da criação de "imagens dialéticas":

Benjamin develops a concept of sound that is equivalent - in its epistemological and metaphysical pressuppositions - to the constitutive properties of the dialectical image. As a sensuous-intuitive, spatio-temporal, haptic-tactile, and historically concrete experience, sound's materiality corresponds closely to that of the dialectical image: the aural thunderclap of sound parallels the visual lightning flash of the image ${ }^{12}$ (HALL, 2010, 83-84).

10 "em Benjamin, uma filosofia da música que entrecruza e investe de sua filosofia do conhecimento e da linguagem, de sua ética e de sua estética a partir de Sulla lingua in generale e sulla lingua dell'uomo até a Origine del dramma barroco tedesco..." (tradução nossa).

11 "O tempo da recordação é o tempo messiânico - tempo da música, da ideia linguistica ou da imagem involuntária" (tradução nossa).

12 "Benjamin desenvolve um conceito de som que é equivalente - em suas presuposições epistemológicas e metafísicas - às propriedades constitutivas da imagem dialética. Como uma experiência sensorial-intuitiva, espaço-temporal, háptico-tátil, e historicamente concreta, a Doutorando PPGL (UFES/2020). Mestrando em Artes PPGA (UFES/2019-). Mestre em Filosofia

PPGFIL (UFES/2017). Professor orientador Licenciatura Letras EAD (IFES/CEFOR/2020). Brasileiro, residente em Vitória-ES. Email: abraao.carvalho@yahoo.com 
Nesta perspectiva interpretamos que a narrativa levada adiante por Cadão Volpato no livro Os discos do crepúsculo (2017), sugere uma investida literária na qual a música suscita o encadeamento e o ritmo de seu elucidar narrativo por meio da memoração, no sentido da música promover a criação de imagens dialéticas tal como pontua Hall diante de sua leitura benjaminiana. Uma narrativa sonora através de imagens dialéticas. Ora, o que nos orienta essa concepção de "imagem dialética", no exercício de interpretação do aparecimento da música na obra Os discos do crepúsculo de Cadão Volpato precisamente? Ou antes ainda, como essa concepção de "imagem dialética" pode ser derivada das formulações estéticas benjaminianas?

As indicações de leitura de Mirko Hall, assim como as de Tamara Tagliacozzo, são precisas em um importante aspecto, a saber, o de tomar como referência para suas leituras o legado da obra de Benjamin que em português, na tradução de João Barrento, ficou intitulado como Origem do Drama Trágico Alemão (2011). Este ponto de convergência enquanto caminho de leitura da obra de Benjamin a partir do referido trabalho, é a pista inicial que temos para nos aproximarmos da perspectiva de uma filosofia da música a partir de Walter Benjamin percorrendo o itinerário de suas formulações estéticas. Logo ao prefácio da obra intitulado curiosamente de Curriculum Vitae, Dr. Walter Benjamin, o ensaísta demarca precisamente seu campo de estudo e interesse: "Desde sempre, os meus interesses se centraram predominantemente na filosofia da linguagem e na teoria estética” (BENJAMIN, Curriculum Vitae, 2011).

O itinerário de Benjamin para chegar na concepção dialética a partir da reflexão estética, do qual parte o sentido dado por Hall para o termo "sonoridade dialética", é marcado por um modo de temporalidade através do qual o ensaísta compreende que é através da concepção de alegoria, que uma tensão dialética entre objeto artístico e sujeito da recepção da experiência estética, promovem a possibilidade de atribuição de sentido, significação e linguagem a partir de tal experiência nos domínios da arte. É neste sentido que Benjamin procura destacar o aspecto dialético da alegoria: 
significação não tem nada da autossuficiência indiferente que encontramos na intenção, aparentemente afim, do signo. O estudo da forma do drama trágico mostrará, mais do que qualquer outro, como no fundo desse abismo da alegoria ruge violentamente o movimento dialético" (BENJAMIN, Alegoria e drama trágico, 2011).

Os discos do crepúsculo de Cadão Volpato, interpretamos ser uma obra de relevante demonstração das possibilidades de se tomar tal narrativa a partir de um projeto estético que visa traçar um olhar, com imagens-símbolo-estéticos-sonoros, de maneira alegórica e emblemática, através da qual podemos ler como uma possibilidade de uma narrativa a partir de uma dialética sonora no sentido atribuído por Hall. Compreendemos que nessa tensão entre objeto reproduzido e o sujeito da experiência estética, reside a essencial abertura de horizonte de compreensão que lança a música nos domínios da dinâmica de uma narrativa literária brasileira contemporânea que atesta a pungência e relevância de imagens dialéticas através de uma narrativa sonora.

A narrativa sonora de Cadão Volpato procura preservar um sentido peculiar para a experiência estética da produção fonográfica por um lado, como um fecundo terreno de reflexão teórica no campo da estética na acepção formulada por Benjamin quando este afirma a respeito do sujeito da recepção estética na condição de ouvinte que é possibilitado a atualizar e ressignificar os sentidos do acontecimento sonoro/musical diante do objeto reproduzido. Uma narrativa da dialética sonora, que segue seu itinerário colocando em um lugar central a música em sua literatura.

\section{REFERÊNCIAS}

ATALLI, J. Bruits: essai sur l'économie politique de la musique. Presses Universitaires de France, 1977.

BENJAMIN, W. Écrits français. Gallimard, Paris, 1991.

Das Passagen-Werk: Die Straßen von Paris: Einer der Grundlagentexte materialistischer Kulturtheorie - Blick in die Jetztzeit des Spätkapitalismus (German Edition). Musaicum Books. Edição do Kindle, 2017.

Origem do drama trágico alemão. Trad. João Barrento. Editora Autêntica. Edição do Kindle, 2011. 
HALL, M. Dialectical sonority: Walter Benjamin's Acoustics of Profane Illumination. Telos 152, pp. 83-102, 2010.

SANTOS, F. Fantasmagoria: a chave para a compreensão da modernidade em Walter Benjamin. In_: Cadernos Walter Benjamin 17, p. 77 -93, 2016.

TRAHAN, J. Phonographie, cinéma et musique rock. Autour d'un impensé théorique chez Walter Benjamin. In_.: Cinémas 241, pp. 103-130, 2013.

TAGLIACOZZO, T. Walter Benjamin e la musica. II glifo ebooks. Prima edizione: gennaio 2013.

VOLPATO, C. Os discos do crepúsculo. Numa, Rio de Janeiro, 2017. Kindle, 2014. Um mistério nos Electric Lady Studios. Formas Breves. Edição do . Você nem imagina. In_: cadaovolpato.com.br, 2010. 